\title{
RESUMEN.
}

En las últimas décadas, las empresas han realizado algo más que negocios, incluyendo en sus prácticas otras modalidades en ámbitos antes inusuales como la filantropía, el campo social, los derechos humanos y el cuidado medioambiental. Este conjunto ha sido definido como Responsabilidad Social Empresarial (RSE). Este concepto no tiene una definición unívoca y es considerada una actividad voluntaria y no compulsiva. Ha recibido un nuevo impulso con los Objetivos del Desarrollo Sostenible de la ONU. A pesar del gran avance, el desarrollo de la disciplina se ha caracterizado por su complejidad puesto que su característica principal es la heterogeneidad de variables y actores a tener en cuenta. En consecuencia, se perciben zonas grises y lagunas sobre las cuales es necesario indagar. El resultado es que compañías aún hoy se escudan tras la imagen de la RSE favorecer el crecimiento empresarial.

Palabras Clave: Responsabilidad Social Empresarial - Objetivos del Desarrollo Sostenible - Ética Social - Balance Social - Zonas Grises.

\section{CRECIMIENTO EMPRESARIAL VS. RESPONSABILIDAD SOCIAL. ¿COMPLEMENTACIÓN O CONFLICTO DE CATEGORÍAS?}

Juan Carlos Armijos ${ }^{1}$

Fecha de recepción: 20 de noviembre de 2019

Fecha de aceptación: 17 de diciembre de 2019

DOI: https://doi.org/10.22370/riace.2019.8.1.2071

1 Escuela de Auditoría y Control de Gestión,Facultad de Economía y Negocios, Universidad Santo Tomás.

Dirección: Av. Ejército Libertador 146, Piso 5, Edificio A, Santiago, Chile.

E-mail: jarmijos@santotomas.cl

Teléfono: [+56]-9-4948-8464 


\section{BUSINESS GROWTH VS. SOCIAL RESPONSIBILITY. COMPLEMENTATION OR CONFLICT OF CATEGORIES?}

\section{ABSTRACT}

Over the last century, companies have transcended the mere act of doing business and have progressively diversified their functions to other areas such as philanthropy, social activity, human rights and environmental care. This set has been defined as Corporate Social Responsibility (CSR). This concept does not have a unique definition and is considered a voluntary and non-compulsive activity. It has received a new boost with the UN Sustainable Development Goals. Despite the great progress, the development of the discipline has been characterized by its complexity since its main characteristic is the heterogeneity of variables and actors to take into account. Consequently, gray areas and lagoons are perceived on which it is necessary to inquire. The result is that companies still hide behind the image of CSR to favor business growth.

Key Words: Corporate Social Responsibility - Sustainable Development Goals Social Ethics - Social Balance - Gray Zones. 


\section{INTRODUCCIÓN}

A lo largo del último siglo, las empresas han trascendido desde el simple hecho de hacer negocios, hacia la diversificación progresiva de sus funciones, pasando a otras áreas como la filantropía, la actividad social, los derechos humanos y el cuidado del medio ambiente, entre otras. Este grupo complejo de actividades y preocupaciones ha recibido diferentes nombres como: ética social empresarial, balance social empresarial, responsabilidad social corporativa, por citar algunas. Con todo, existe un consenso entre académicos, empresarios y funcionarios públicos en conceptualizarlo como Responsabilidad Social Empresarial (RSE). Este concepto no tiene una definición única, siendo además considerada como una actividad voluntaria y no compulsiva.

Si bien el concepto sobre RSE no es nuevo, este cobró un impulso decisivo con el establecimiento de Agenda 2030 de las Naciones Unidas en donde se establecen los 17 Objetivos para el Desarrollo Sostenible (ODS), otorgando un rol protagónico al sector privado para su efectivo cumplimiento. La RSE se ubica así en el centro de la escena siendo su estudio un tema actual dentro de la economía, las ciencias empresariales, y aún, en las ciencias sociales. Este trabajo pretende ser un aporte y una reflexión al respecto.

El desarrollo de la disciplina se ha caracterizado por su complejidad puesto que su característica principal es la heterogeneidad de variables y actores a tener en cuenta. Si bien el desarrollo es universal, cada país y región tienen sus particularidades. Lo mismo acontece con el tamaño de las empresas (grandes o PYMES), si son públicas 0 privadas, en este último caso si son de capitales nacionales o extranjeras. Del mismo modo, cada sector o rubro empresarial tiene una dinámica propia, aunque en general todos han progresado. Al no existir un organismo internacional que regule y mida la responsabilidad comienzan las divergencias y los problemas para recrear el actual estado del arte.

Estas dificultades dan lugar a lo que denominamos zonas grises o lagunas, aspectos que implican diferentes formas de concebir o interpretar la RSE, distintos modos de medirla, y diversas estrategias e intereses en las acciones de las mismas. En consecuencia, cabe preguntarse si la RSE es una disciplina 0 actividad propia e ineludible en una compañía, o es solo un medio atractivo para fomentar el crecimiento empresarial. El trabajo se preocupa mayormente por abordar estas cuestiones en América Latina.

En ese sentido, el estudio tiene como alcance realizar un aporte al ámbito académico, sirviendo como un elemento más de la discusión y reflexión académica sobre la temática. Con esta motivación la presente investigación se centra en responder ¿Cuáles son los aspectos de la RSE que deben progresar para superar el enfoque que la transforma de un simple medio publicitario hacia el potenciamiento del crecimiento empresarial? Y a partir de la misma, como puede ayudar a ello el aferramiento a los ODS para convertir a la RSE definitivamente en un elemento 
central inherente al ámbito de los negocios. En este marco, la investigación se plantea como objetivos específicos:

- Indagar acerca del Concepto de RSE, sus alcances y limitaciones.

- Describir la situación RSE en el mundo en general y América Latina en particular.

- Reflexionar sobre el impacto que el concepto de RSE ha producido en el ámbito de los negocios empresariales.

- Identificar aportes y debilidades de la RSE en el accionar de las empresas.

Para su desarrollo, este estudio junto con la introducción será dividido en una serie de apartados, en los que se incluirá en segundo término el contexto de la RSE, en tercer lugar, a los ODS como punto de no retorno, cuarto, el relevamiento de datos, quinto, la síntesis y el análisis de la información, destacando ahí brevemente lo que acontece a nivel mundial, y, por otro lado, algunos rasgos de América Latina. En sexto lugar, se plantea la discusión o debate acerca de las zonas grises, y finalmente las conclusiones.

\section{CONTEXTO DE LA RSE.}

Actualmente, es posible afirmar que la actividad empresarial trasciende ampliamente el objetivo utilitarista de obtener el máximo de ganancia posible. Del mismo modo, se puede señalar que una empresa va más allá de gozar del prestigio alcanzado por el producto o servicio que brinda, y ser reconocido por gobiernos y otras empresas por ello. El sector privado en cierta forma cumple funciones en el ámbito social que complementan a las del sector público, creando un nuevo tipo de relación triangular entre el Estado, las empresas y la sociedad. Este rol que ocupa hoy el empresariado es lo que comúnmente se ha denominado Responsabilidad Social Empresarial (Cardona Acevedo y Duque Orozco, 2013; Alvarado Herrera y Schlesinger Díaz, 2008).

Resulta llamativo o paradójico, pero en la actualidad no existe un consenso 0 definición universal del concepto de RSE, sino más bien, múltiples definiciones e interpretaciones sobre el mismo. En ese sentido, Porto y Castromán (2006) resaltan que no se ha logrado una definición de la RSE comúnmente aceptada ni existe institución internacional alguna con el poder de desarrollarla.

Por ejemplo, varios autores al respecto, denominan a la RSE como situaciones donde la empresa se compromete y cumple acciones que favorecen el bien social, más allá de los intereses de la empresa y por sobre lo que se espera como cumplimiento de la ley (McWilliams, Siegel y Wright, 2006). Por su parte, Remache, Villacis y Guayta (2017), definen a la RSE como la contribución voluntaria a la mejora social, económica y ambiental de las empresas, con el objetivo de mejorar su valoración competitiva y su valor añadido. Por último, Antelo \& Robaina (2015) citado en Pérez, Espinoza y Peralta (2016) sostienen que "la responsabilidad social 
empresarial es el compromiso continuo de contribuir al desarrollo económico sostenible, mejorando la calidad de vida de los empleados y sus familias, así como la de la comunidad local y de la sociedad en general" (p.59).

No obstante, desde este trabajo se entiende al igual que Aguilera Castro y Puerto Becerra (2012, p.5) a la Responsabilidad Social Empresarial como "el compromiso que asumen las empresas hacia la sociedad en beneficio del desarrollo sostenible, es decir, es el equilibrio entre el crecimiento económico y el bienestar social". La RSE actúa como medio a través del cual se erigen relaciones de beneficio recíproco entre los objetivos empresariales y los intereses colectivos de la sociedad. Las empresas se valen de tales relaciones para impulsar su crecimiento y garantizar la sostenibilidad integral del negocio ${ }_{1}$.

La RSE es una decisión de carácter voluntario por parte de la empresa. Es esta la que determina deliberadamente si asume o no ese compromiso. Por lo tanto, se trata de una contribución activa y voluntaria de las empresas en el mejoramiento social, económico y ambiental. Adquiere de este modo una dimensión o significado ético. Coincidimos con Correa Jaramillo (2007) en que el criterio de voluntariedad no obliga legalmente a las organizaciones a ser socialmente responsables, pero el mercado sí ha aprendido a diferenciar entre empresas comprometidas con causas sociales y aquellas que no lo están. Siguiendo al autor ser socialmente responsable no significa solamente cumplir plenamente las obligaciones jurídicas, sino también ir más allá de su cumplimiento invirtiendo más en el capital humano, el entorno y las relaciones con los interlocutores.

Actualmente la RSE se lleva adelante en todo tipo de empresas, vale decir, públicas y privadas, grandes, medianas o pequeñas, y compañías de cualquier sector económico. Tal concepto tiene básicamente una aplicación universal, esto es, se practica en todo el mundo. Si bien tuvo su origen en los países desarrollados, en el presente a la par de la globalización se ha extendido hacía América Latina, Asia y África, ya que la responsabilidad social de las empresas contribuye a su crecimiento y competitividad.

Es necesario aclarar que lo que hoy se conoce como RSE fue producto de un proceso evolutivo en el ámbito empresarial que puede rastrear sus orígenes a fines del siglo XIX. El primer antecedente conocido es la Ley Antimonopolio Sherman de 1890. La misma dejó en evidencia la necesidad de regular y controlar el entorno empresarial, procurando así proteger y resguardar los intereses de la sociedad que se vieran afectados por tales acciones.

En la primera mitad del siglo XX comienzan a identificarse empresas con cuyo accionar voluntario participan espontáneamente procurando alcanzar el bienestar de la sociedad practicando generalmente la filantropía. La responsabilidad de estas ante la sociedad se acrecienta luego de la crisis económica de 1930 con

1 Los estudiosos de la materia suelen hacer una distinción entre RSE y Balance social, comprendiendo a este último concepto como una evaluación sistemática en base a información estadística que pretende conseguir un crecimiento sostenido que valora la labor de una empresa y su impacto en la sociedad en base a un análisis de las dimensiones sociales y éticos (Correa Jaramillo, 2007). Actualmente, algunas compañías confunden RSE y Balance Social, que, si bien están relacionadas, son categorías diferentes. 
la quiebra masiva de empresas, el drástico aumento del desempleo y la pobreza. Con posterioridad a la Segunda Guerra Mundial, se profundiza la cuestión social y la sociedad comienza a tomar conciencia que el sector privado puede colaborar en su solución. Además, se incorporan nuevos temas como el cuidado del medio ambiente. En esa dirección, el afán de las empresas por explotar los recursos naturales obligó a los estados (e incluso a organismos internacionales) a intervenir elaborando reglamentos, leyes y demás disposiciones tendientes a cuidar e incluso recuperar el medio ambiente. Correa Jaramillo (2007, p.90), al respecto menciona, que es en este momento en que "la empresa, el Gobierno y la sociedad se han ido interrelacionando, de tal forma que han ido cambiando sus papeles originales hacia actuaciones en las que las decisiones de los distintos participantes no son independientes, sino que suelen estar influenciadas, 0 incluso impuestas, por otros grupos sociales". En la posguerra, comienza a hablarse de responsabilidad corporativa.

Aun así, desde algunos sectores académicos se manifestaban resistencias ante esta tendencia. Milton Friedman (1970) sostenía que "la única responsabilidad de la empresa hacia la sociedad es la maximización de beneficios a los accionistas dentro del marco legal y ético del país". El economista consideraba que los problemas sociales se debían encontrar solución con el sistema de libre mercado y no ser una mera responsabilidad del empresario ${ }_{2}$.

En el decenio de 1980, se observa de manera sistémica la práctica de la RSE voluntaria en momentos en que se internacionalizaban los capitales y la economía comenzaba a basarse en la oferta. Esta acción voluntaria surge como respuesta a los reclamos de la sociedad tomando medidas voluntarias en favor del crecimiento, el desarrollo y el bienestar social. Por último, en los años noventa con la globalización, la competitividad se convierte en un elemento central. Tanto para su supervivencia y expansión, las empresas procuraban atraer clientes por medio de argumentos diferenciales. Uno de estas posibilidades es la acción social responsable por parte de una compañía. Se afianza así la dimensión ética tanto en lo que respecta a los empresarios como a las empresas. Comienza a hablarse de una ética de la competencia. En ese sentido, Carrol (1991) introduce diferentes conceptos como la política pública empresarial, la ética empresarial y la teoría de los stakeholders o grupos de interés. Sin embargo, en el fondo se trata en todo momento de incorporar el concepto de RSE al clima de negocios y la rentabilidad, esto es, no solo maximizar los beneficios económicos sino también contribuir al bienestar social y al cuidado del medio ambiente entre otros aspectos.

2 También es común encontrar críticas a la RSE. A modo de ejemplo se la cataloga como una forma de publicidad empresarial donde las compañías se aprovechan para vender más productos, 0 bien, es utilizada para justificar como un fin bueno un principio negativo para el hombre, como el caso se las empresas de cigarrillos, que compran el tabaco a campesinos pobres manifestando que así les dan empleo y que promueven su desarrollo, contrarrestando así los ataques recibidos contra lo nocivo de fumar. Por otra parte, algunos economistas piensan que, si las empresas sacrifican parte de sus ganancias en nombre de la responsabilidad social, se podrían volver menos atractivas para inversionistas, trabajadores y consumidores, afectando de ese modo su rentabilidad (Barroso Tanoira, 2008). 


\section{EL PUNTO DE NO RETORNO: LOS ODS.}

Como se ha mencionado anteriormente, la RSE ha sido ampliamente incorporada por todo el espectro del sector privado como un elemento esencial 0 inherente a su actividad. Sin embargo, inmediatamente surgen ciertas dudas, algunos interrogantes propios de la vaguedad del concepto, 0 más que nada de su aplicación. Algunas preguntas son un verdadero enigma como por ejemplo ihay criterios específicos a seguir? En caso de haberlos ¿Cuáles son esos criterios? ¿Quién los determina? Además, es posible preguntarse cómo se mide la RSE y sobre todo quién la mide.

Ante este tipo de lagunas 0 áreas grises, se han incorporado una gran cantidad de actores de toda índole (públicos, privados, nacionales e internacionales) para tratar de resolver estas cuestiones o parte de ellas. En ese sentido, si bien sigue habiendo imprecisiones, el margen de las mismas se ha vuelto más estrecho. El resultado de todo este proceso ha sido el surgimiento de teorías, normas, índices, estándares, certificaciones, entre otras. En esa dirección, Duque Orozco, Cardona Acevedo y Rendón Acevedo (2013) ${ }_{3}$ plantean que el mismo concepto de RSE sugiere una renovación constante que ha ido posibilitando su maduración. Esto ha tenido un impacto en las formas de medición que ha desembocado en conjunto de normas, guías y metodologías para la comprensión de la RSE, pero también por otra parte implican la confusión frente a cuáles deben ser los parámetros básicos de operación.

Este proceso se ha enmarcado dentro de otro, más general y amplio, pero a la vez más determinante, denominado bajo el concepto de Gobernanza Global. La primera gran iniciativa han sido los ocho Objetivos de Desarrollo del Milenio (ODM) establecidos en la Cumbre del Milenio en el año 2000 con vistas a ser alcanzados en 2015. Sin embargo, en ese año luego de una revisión y un nuevo consenso se incorporan otros nueve objetivos. El resultado han sido los 17 Objetivos del Desarrollo Sostenible (ODS) de las Naciones Unidas que se extienden para su concreción a 2030. La RSE se ha insertado y amoldado a este nuevo marco de políticas globales. Principalmente se destaca el Objetivo 17, Alianzas para lograr los objetivos, al señalar la necesidad de formar alianzas entre gobiernos, empresas (sector privado) y sociedad civil.

En este contexto global, en lo que a este trabajo le incumbe, sobre la RSE se han conformado una suerte de trípode y sus correspondientes relaciones triangulares entre la Gobernanza Global, las Empresas y la Ciudadanía. En primer lugar, El consenso internacional en la gobernanza global es una necesidad urgente para afrontar desafíos comunes como el cambio climático, la economía circular, los

3 Los autores en un gran trabajo ponen énfasis en el proceso de institucionalización de normas para medir la RSE y enumeran algunas de ellas: Pacto Mundial, el Global Reporting Initiative (GRI), SA 8000, AA 1000, la ISO 26000, AECA, los indicadores Ethos de RSE.

4 Ellos son: Erradicar la pobreza extrema y el hambre (ODM 1), Lograr la enseñanza primaria universal (ODM 2), Promover la igualdad entre los sexos y el empoderamiento de la mujer (ODM 3), Reducir la mortalidad de los niños

5 Ver: https://www.un.org/sustainabledevelopment/es/objetivos-de-desarrollo-sostenible/ 
derechos, el futuro del trabajo o los Objetivos de Desarrollo Sostenible. En segundo término, una mayoría temprana de las empresas globales ya ha conseguido cimentar la sostenibilidad como un área prioritaria para el negocio. Por último, el ciudadano se encuentra cada vez más informado. Actúa de este modo como un consumidor consciente está en la línea de salida, impulsado por los hábitos de vida saludable (Informe Forética, 2018).

Estos marcos de interacciones propias del siglo XXI han producido a nuestro parecer un punto de no retorno. Las empresas están insertas en este circuito, y en un entorno competitivo cualquier compañía que no lo contemple no puede sino causarse un perjuicio a sí misma. Aún más, esta tendencia tiende a profundizarse. El Informe Forética de 2018 plantea que hay cinco tendencias que darán forma a la sostenibilidad en los próximos años: 1) el cumplimiento de los ODS, 2) el riesgo que provoca el cambio climático, 3) la economía circular como respuesta a la escasez de recursos, 4) la aplicación de los derechos humanos en las cadenas de suministro globales, y 5) el futuro del trabajo y la sociedad 5.0. En consecuencia, el mundo, los gobiernos y la ciudadanía esperan que las empresas actúen como aceleradoras de la sostenibilidad actualizándose y perfeccionándose en esa dirección (Informe Forética, 2018).

A lo largo de estos apartados, es posible observar que el desarrollo de la RSE es producto de un doble proceso que a su vez retroalimenta a las empresas. De un lado, un proceso local o nacional en el que las empresas a la par de sus objetivos comerciales deben contribuir al desarrollo económico, social y cultural de su país y de su población. Por otro lado, donde las compañías están cada vez más asociadas a brindar respuestas a las grandes problemáticas globales y para las que cada vez hay más exigencias, normativas y rendiciones de cuentas.

\section{LEVANTAMIENTO DE DATOS.}

La metodología empleada en este estudio es de tipo cualitativo respecto de la investigación social. Para levantar la información, se tuvieron presentes tres clases de fuentes secundarias representadas en artículos de índole académica, informes y encuestas realizadas por organizaciones, entes gubernamentales o de las mismas empresas, y artículos actuales de prensa 0 entrevistas en medios masivos de comunicación.

Los artículos académicos recabados han permitido introducirnos en la materia, contextualizar el surgimiento y desarrollo de la RSE, así como familiarizarnos con los autores clásicos y las discusiones específicas que se producen en la actualidad.

Por otra parte, elementos significativos para este trabajo han resultado los distintos informes y encuestas llevados a cabo por entes gubernamentales, organizaciones empresariales o de la sociedad civil y de las mismas empresas. Este elemento ha resultado de vital importancia al ser considerado los únicos registros 
estadísticos con datos sistematizados de acceso público. Si bien se trata de datos duros, cuantitativos, son quienes a posteriori permiten trazar las problemáticas, polémicas y elaborar conclusiones al respecto. Específicamente recolectamos la información de dos informes por ser los más actualizados y con una gran cantidad y diversidad de datos estadísticos: el Informe Forética 2018 y el de la consultora KPMG del mismo año. Además, para el caso de Colombia se recurrió al Informe de la Asociación Nacional de Empresarios de Colombia de 2017 por la seriedad y riqueza de sus datos.

Por último, la incorporación de artículos periodísticos y entrevistas de este tipo, si bien muchas veces no son aconsejables, se las ha incluido a fin de obtener datos específicos sobre determinados países o sectores, como ha sido el caso de Argentina.

A través de esta información estadística, se ha podido describir, recrear y contextualizar la situación de la Responsabilidad Social Empresarial en el mundo y en parte en América latina. El siguiente paso fue elaborar un estudio analítico que intentó dar cuenta de los objetivos planteados.

\section{SÍNTESIS Y ANÁLISIS DE LA INFORMACIÓN}

\subsection{BREVE PANORAMA MUNDIAL}

Como quedó expresado en apartados anteriores, la RSE se practica actualmente en todo el mundo, aunque marchan a diferente ritmo. Actualmente, a la vanguardia de este proceso se encuentran los países de la Organización para la Cooperación y el Desarrollo Económico (OCDE), Los países miembros en este ámbito impone condiciones, regulaciones, normativas y exigencias mayores a sus empresas. Sin embargo, las empresas que operan en estos países han adquirido una mayor conciencia, ética y hasta una cultura de responsabilidad.

El Informe Forética 2018 es, en opinión de este trabajo, ilustrativo de esta situación puesto que relaciona, por un lado, acertadamente la competitividad económica de los países con el desempeño de los ODS, y por el otro lado, el rol de las empresas en el crecimiento sostenible. En cuanto al primer punto, el informe analiza 133 casos y encuentra entre los países tres niveles de rendimientos diferentes. Un 7\% es considerado virtuoso ya que su desempeño en ODS es concebido superior al esperado en función de su desempeño económico. La gran mayoría (67\%) encuentra equilibrado su desempeño en ODS y su nivel de competitividad (fair players). Y, por último, $20 \%$ de los países presentan un desempeño en ODS decididamente inferior a su nivel de competitividad (free riders) (Informe Forética, 2018).

Por medio de adherir a lo predispuesto en los ODS, una gran cantidad de empresas han logrado poner un mayor énfasis en el impacto a gran escala de las prácticas de 
responsabilidad social. El informe da cuenta de tres etapas o ciclos que han llevado adelante las empresas. El primero comprendido entre 1995-2010 dominado por los optimistas, un pequeño grupo de empresas adelantadas siguiendo los consejos de académicos establecen las primeras herramientas y marcos de actuación para empresas como son como las normas de gestión SA 8000, AA1000, la española SGE 21, y los estándares de reporte, como Global Reporting Initiative. Además, comienzan a utilizar nuevas herramientas de gestión de la responsabilidad social y publican las primeras memorias de sostenibilidad por parte de las compañías más importantes.

En la segunda etapa (2010-2018) emergen una gran cantidad y variedad de actores. Las compañías profundizan la cuestión de la sostenibilidad como un elemento central de la rendición de cuentas. Para 2017, tres de cada cuatro empresas de las más relevantes publican memorias y diseñan estrategias de sostenibilidad cada vez más ambiciosas. Durante este proceso de maduración, irrumpe un tercer actor, que hasta el momento había tenido un papel secundario, el sector público. Los gobiernos se erigen en coarquitectos el proceso de la sostenibilidad. En 2015, la sostenibilidad trasciende el ámbito nacional o regional e ingresa en la gobernanza global de la mano de la Agenda 2030 con los ODS incorporando al sector privado como copartícipe y al mismo tiempo el Acuerdo Climático de París de ese año introduce a la cuestión ambiental como otro eje ineludible a tener en cuenta (Informe Forética, 2018, p.30). 


\section{Figura l:}

Principales variables de la RSE.

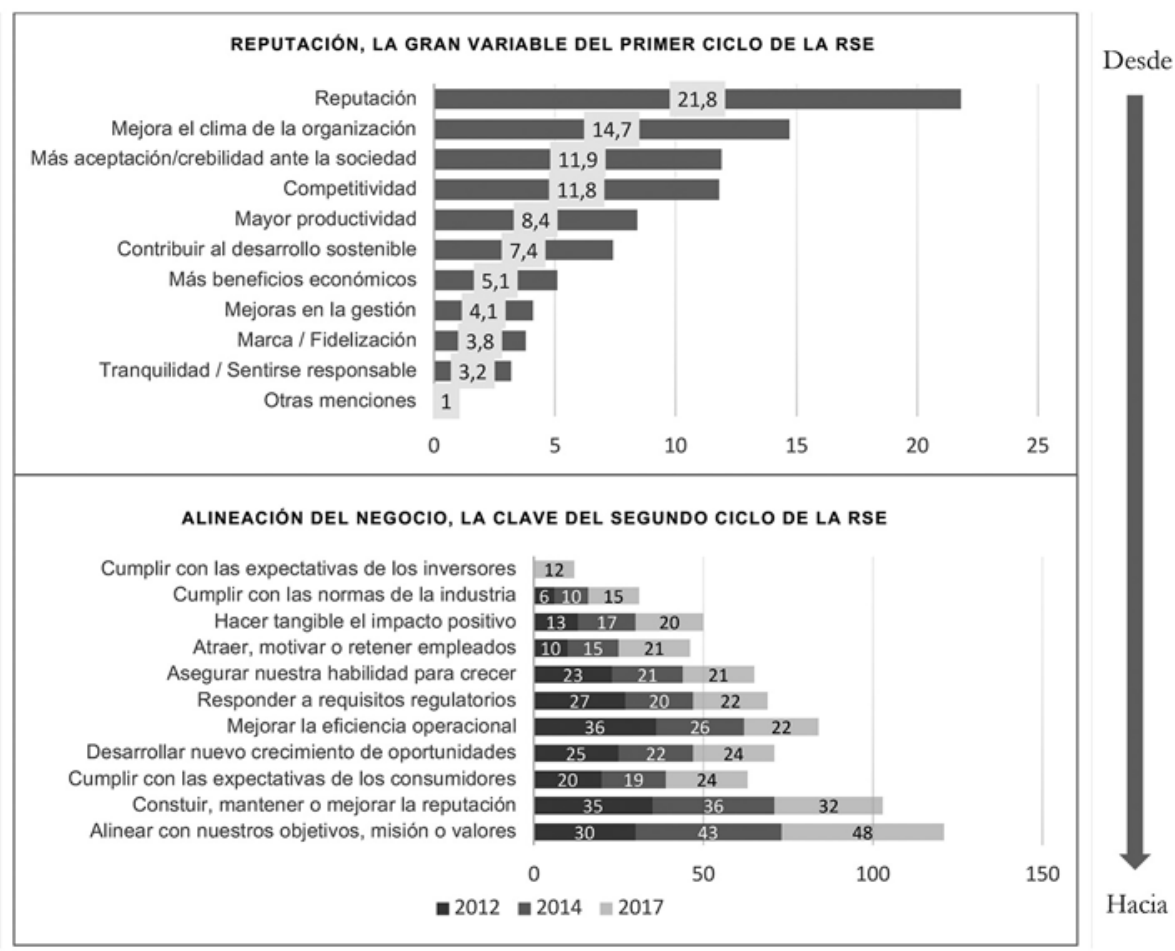

Fuente: Forética 2018.

En este período, queda manifiesto que las agendas de responsabilidad social de las empresas han pasado de un estado de baja madurez a un nivel de gran prioridad en economías de escala de las prácticas de sostenibilidad (Informe Forética, 2018, p.30). Esta situación pudo alcanzarse recién tras sobreponerse a lo que se conoció como "pecado de la ortodoxia", una práctica muy tradicional en agendas menos maduras en el que las compañías diluyen su esfuerzo en RSE al preponderar los estándares a la propia realidad de la empresa.

Por último, un tercer ciclo, desde 2018 hasta el presente, donde predomina el pragmatismo y la incorporación de actores que venían en lugares retrasados en la materia, esto es, PYMES, empresas con escasa innovación, y por otra parte los consumidores. Se vuelve más rigurosa la legislación, sobre todo en materia ambiental. El factor tecnología o innovación introduce al mercado sucesivamente nuevos productos proveyendo soluciones para viejas problemáticas, penetrando de este modo en la sociedad elevando los estándares. La RSE, finalmente, plantea un cambio de enfoque de toda la actividad empresarial, desde la relación y expectativas de la empresa respecto al entorno, pasando por la rendición de cuentas, llegando hasta el qué y el cómo se producen sus productos y servicios. 
Este informe es complementado con otro elaborado por la consultora KPMG (2018) en el cual pueden percibirse datos estadísticos concretos sobre las tendencias globales de la RSE. Tomando como base 4.900 compañías se establece un crecimiento de elaboración del Reporte de responsabilidad corporativa desde 1993 hasta 2017 (KPMG, 2018, p.12) (ver figura II).

\section{Figura II:}

Evolución del reporte sobre responsabilidad corporativa desde 1993.

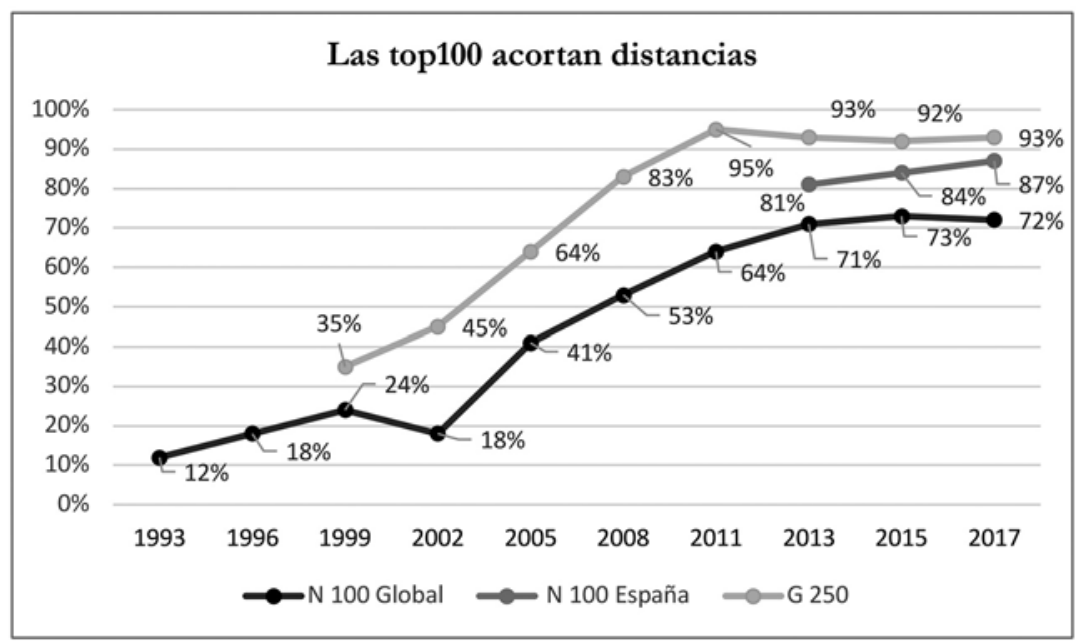

Base: N100 Global (4.900 compañías). G250 (250 compañías)

Fuente: Elaboración propia con base en: Estudio KPMG sobre reporting de responsabilidad corporativa 2017.

En cuanto a desagregar compañías por sectores, este informe destaca que para 2017 más del $60 \%$ de las empresas de todos los sectores realizan reportes sobre sus políticas de responsabilidad corporativa. Más de 2/3 de las empresas de todos los sectores han mejorado en 2017 (a excepción del Retail) con la particularidad que los cuatro sectores considerados más rezagados en 2015 (Sanidad, Trasporte \& Ocio, Industria Manufacturera y Metales, y Retail). Más de $75 \%$ de las compañías consideradas por el informe incluyen en sus informes anuales tanto información financiera como no financiera (reporte integrado) (Figura III). 


\section{Figura III:}

Responsabilidad Social Empresarial por Sectores.

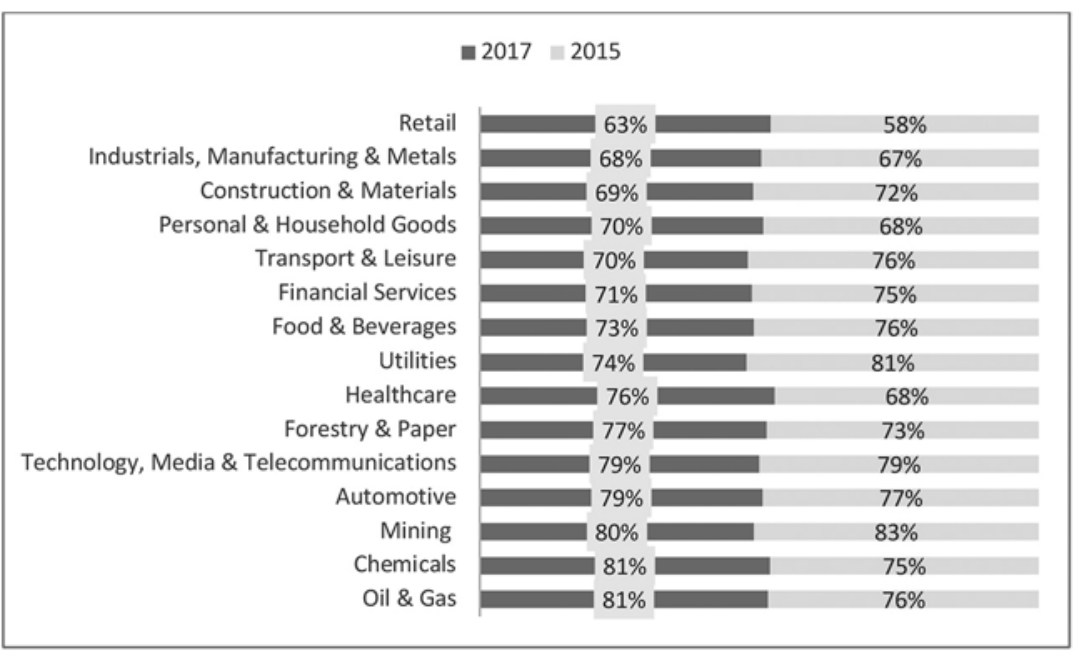

Fuente: Elaboración propia con base en: Estudio KPMG sobre reporting de responsabilidad corporativa 2017.

\section{2. ¿QUÉ ACONTECE EN AMÉRICA LATINA? ALGUNAS CONSIDERACIONES.}

Como quedara resaltado en el apartado anterior, América Latina ha sido una de las regiones del mundo que ha realizado uno de los mayores progresos en materia de RSE. Las empresas radicadas en esta región realizan cada vez más reportes sobre sus acciones responsables. Sin embargo, este panorama no ha sido uniforme. Cada país ha presentado realidades diferentes y dentro de los mismos, compañías de distintos sectores se han destacado realizando también acciones diversas. Al respecto, es importante mencionar, que, si bien la RSE es discutida en varios países de Latinoamérica, este estudio enfoca su análisis en tres países de la región.

Un lugar destacado y de vanguardia en RSE ocupa Colombia. Este país no ha sido ajeno a las tendencias mundiales y actualmente conviven diferentes maneras a través de las cuales las empresas son socialmente responsables. Para ello, nos basamos en el informe de la Asociación Nacional de Empresarios de Colombia (ANDI) de 2017 titulado "Panorama de la gestión social de 500 empresas en Colombia" ${ }_{6}$. Los resultados ilustran la diversidad y la complejidad que este tema ha adquirido en Colombia.

6 Se trata del análisis de los resultados de la Segunda Encuesta de Arquitectura Social Estratégica realizada por la Asociación Nacional de Empresarios de Colombia (ANDI) entre enero y julio de 2017. Para ello se seleccionaron 500 grandes y medianas empresas de las principales ciudades del país y de todos los sectores económicos, a cuyos responsables de los temas sociales se encuestó de modo presencial. 
Ente sus conclusiones, el informe (ANDI, 2017, p.4) destaca como positivo que las personas al interior de las empresas encargadas de los temas sociales están cada vez mejor calificadas. De acuerdo a este informe, el $52 \%$ de las empresas no tienen un área específica que maneje la estrategia social. En aquellos casos que sí la tienen, la llaman gestión humana, responsabilidad social, o sostenibilidad, y cuenta en su mayoría con más de tres personas dedicadas a la gestión social. En términos del lugar que ocupa el área dentro de la empresa, encontramos que la gran mayoría (77\%) reporta y rinde cuentas directamente a la gerencia 0 a la presidencia de la compañía siendo un indicador de la relevancia que está adquiriendo la RSE (ANDI, 2017, p.5).

Además, entre los puntos destacables, las empresas le están dando cada vez una mayor importancia a los temas sociales como parte del negocio, y se prioriza cada vez más el trabajo en alianzas. El 70\% de las empresas afirman que su estrategia social se encuentra alineada con la operación del negocio e indican que se desarrolla en su zona de influencia (69\%), principalmente Antioquia, Bogotá, Valle y Atlántico (ANDI, 2017, p.5). Las acciones sociales que realizan las empresas son generalmente de mitigación de impactos del negocio (77\%), programas para sus empleados y familias (76\%), y donaciones (64\%). El 36\% dice llevar a cabo acciones relacionadas con su cadena de valor. También un hallazgo interesante es que el $35 \%$ hacen voluntariado corporativo, y el 32\% inversión de impacto. El porcentaje de las acciones para mitigar los impactos del negocio (77\%) aumentó significativamente desde 2015 cuando no superaba el 50\%. También, Las acciones de las empresas en este ámbito se concentran en las áreas de medio ambiente (64\%) y educación (46\%) (ANDI, 2017, p.5).

Las poblaciones principales a quienes las empresas dirigen sus acciones sociales son personas en situación de pobreza o pobreza extrema (38\%), niños, niñas y adolescentes (37\%), empleados y sus familias (34\%), primera infancia (29\%), adultos mayores (22\%), mujeres (18\%) y jóvenes (18\%). En menor medida benefician a población víctima de la violencia, personas en condición de discapacidad, minorías y reintegrados de grupos al margen de la ley (ANDI, 2017, p.7). Otro de los resultados importantes de la encuesta es que el $35 \%$ de las empresas hace voluntariado, 3 puntos porcentuales más que en el 2015 (ANDI, 2017, p.5).

No obstante, entre los puntos negativos, el informe acusa los cortos periodos de planeación que en su gran mayoría son proyectos a un año (ANDI, 2017, p.10). También, remarcan el desconocimiento de los presupuestos. En cuanto a las donaciones, se evidenció una reducción en el número de empresas que hacen donaciones pasando de un $70 \%$ en 2015 a un 64\% en 2017. Estas donaciones están direccionadas principalmente a educación (53\%), ayuda humanitaria (48\%), y arte, deporte y cultura (34\%) (ANDI, 2017, p.6).

Del mismo modo, el $41 \%$ de las compañías no miden ni evalúan sus inversiones sociales. Si bien el $54 \%$ dice realizar medición de impacto, los indicadores 
con lo que los hacen en realidad miden gestión y resultados. Para reportar sus intervenciones sociales, el 55\% utiliza un reporte interno, y sólo el 13\% reportan bajo la metodología GRI (Global Reporting Initiative) como es recomendado. El $41 \%$ de las empresas no mide ni evalúa sus intervenciones sociales, esto quiere decir que hay 205 empresas que invierten sumas importantes de dinero en proyectos sociales y no tienen ninguna información sobre los resultados que obtienen ni sobre la rentabilidad de sus inversiones. Las empresas que sí evalúan, en su mayoría hacen evaluaciones de gestión y de resultado (ANDI, 2017, p.10).

Por último, casi la mitad de las empresas señalan la falta de recursos financieros como la principal dificultad al realizar inversión social privada (ANDI, 2017, p.9). Y la misma cantidad no conoce qué son los Objetivos de Desarrollo Sostenible (ODS). De 257 empresas que sí lo hacen, el 78\% asocia los ODS con una oportunidad para el sector privado. Por último, al indagar sobre los Objetivos de Desarrollo Sostenible, la mitad de las empresas no los conocen. En términos generales, las empresas asocian los ODS con una oportunidad para el sector privado (ANDI, 2017, p.11).

En el caso de México, la mejora de las compañías en materia de RSE es por demás ilustrativa. En primer lugar, al ser considerado como miembro de la OCDE, para las firmas, los controles, la rendición de cuentas, la transparencia, y las exigencias al pertenecer a esta organización son mayores que para la mayor parte de Latinoamérica. En ese sentido, es una ventaja para el fomento y progreso de la RSE. Además, en este país aquellas empresas que son socialmente responsables se les conceden el Distintivo Empresa Socialmente Responsable (ESR) otorgado por el Cemefi (Centro Mexicano para la Filantropía). En 2001 por primera vez se otorgó a ocho empresas, y en 2014, se alcanzó la cifra de 933 compañías (Informe Cemefi, 2018). A través de este Distintivo, las firmas acceden a beneficios como posibilidad de financiamientos para proyectos de responsabilidad social.

Una primera aproximación de interés es el estudio que realizó Barroso Tanoira (2008) sobre cuarenta empresas en la ciudad de Mérida, Yucatán. Si bien se trata de un trabajo que data de una década atrás, es localizado y limitado en cuanto al número de empresas, algunas conclusiones parciales resultan por demás de útiles e ilustrativas. Desde este trabajo se pretenden destacar específicamente dos conclusiones. En primer lugar, la existencia de una confusión sobre el concepto de RSE y el hecho de que algunas empresas que se asumen socialmente responsables, pero no lo son en su totalidad. Para la mayoría, la RSE es mejorar la calidad de vida del personal y la contribución a la sociedad. Sin embargo, sus acciones se orientan principalmente hacia el trato e imagen ante el cliente, con el objetivo de vender más. Poco relevante resultó el cuidado y la preservación del medioambiente ${ }_{8} 0$ practicar

7México ingreso a la OCDE en 1994. Chile fue el segundo país latinoamericano y el primer sudamericano al ingresar en 2010. Actualmente, se sostiene que el ingreso de Colombia sería en el corto plazo mientras que también se encuentran avanzadas las negociaciones con Costa Rica.

8Las acciones mencionadas en el informe se relacionan más con el cliente, la calidad y la operación del negocio (37.1\%) y los empleados (25.8\%). Aunque en las respuestas a las preguntas anteriores el cuidado al medio ambiente fue poco mencionado, en ésta reconocieron que efectúan acciones de reciclaje (20\%). En otro trabajo en esa misma fecha, Ramírez Alcántara y Morales Espinoza (2008) sustentan la hipótesis de que la Política Gubernamental y Empresarial relativa al desarrollo sostenible, 
la filantropía. Por lo tanto, en ninguna de las empresas se cumple el concepto completo, por lo que no pueden llamarse socialmente responsables en el sentido amplio y estricto de su significado.

En segundo lugar, se reconoce explícitamente que la práctica de RSE tiene en el fondo un fin mercantilista cuando la misma debería ser parte del actuar cotidiano. Por ejemplo, con mucha frecuencia se identificó la necesidad de implantar acciones de RSE para mejorar la imagen y atraer a más clientes (90\%). Además, el beneficio más mencionado fue el que los clientes reconocen a la empresa y se acercan más a ella, obteniendo más ventas (62.9\%) (Barroso Tanoira, 2008).

No obstante, una década después de ese trabajo, la situación parece haber progresado sustancialmente. Las empresas han mejorado su compromiso, sus prácticas y los mecanismos de medición de estas. En 2018 el Cemefi y la Alianza por la Responsabilidad Social Empresarial por México (AliaRSE), organizaron el XI Encuentro Latinoamericano de ESR, cuyo eje temático fue La Responsabilidad Social Empresarial (RSE), y los Objetivos de Desarrollo Sostenible (ODS). En el evento 877 empresas recibieron el Distintivo. Adicionalmente, 117 empresas se sumaron a la iniciativa del 1\% de Inversión Social, que busca que las compañías que tienen el Distintivo ESR se comprometan públicamente a donar ese porcentaje de sus utilidades antes de impuestos a causas de beneficio social (Informe Cemefi, 2018). Por otro lado, se realizó el XIII Seminario Internacional de Mejores Prácticas de RSE en Guadalajara, Jalisco. El fin del Seminario fue difundir y reconocer los proyectos empresariales de México y América Latina que obtuvieron el Reconocimiento a las Mejores Prácticas de RSE por su originalidad y capacidad de reproducción en otras latitudes. Se recibieron 104 prácticas —82 implementadas en México y 22 en América Latina - entre las que se seleccionó a 18 como ganadoras: trece de México, dos de Uruguay, una de Colombia, otra de Ecuador y una más de El Salvador (Informe Cemefi, 2018).

A pesar de los progresos en la materia, desde la perspectiva de este trabajo, persiste el interrogante de hasta qué punto las empresas en la actualidad han abandonado el enfoque mercantilista de las RSE y se ha logrado arraigar un concepto integral, completo de la RSE.

En Argentina la RSE ha evolucionado por más de 20 años. Desde sus orígenes en los noventa hasta el nuevo siglo se registró un cambio de paradigma en el enfoque de RSE. En sus inicios se la asociaba a "hacer donaciones", pero el enfoque se fue resignificando y en la actualidad se la relaciona con la excelencia en la gestión que exhiben las empresas. En otras palabras, la forma en que la empresa se desenvuelve frente a la comunidad y qué tipo de gobierno y sociedad está ayudando a construir (D'angelo, 2009). El nacimiento del Instituto Argentino de Responsabilidad Social Empresaria (IARSE) $)_{9}$ en el año 2000 ilustra ese cambio de paradigma.

es decir, el desarrollo con responsabilidad y respeto del entorno con el máximo aprovechamiento de los recursos, se encontraba en proceso de definición por lo que el desarrollo ambiental era todavía incipiente.

9 El sitio web de la organización dispone de una gran cantidad de datos e información. Disponible: http://www.iarse.org/ 
A pesar de los vaivenes y las dificultades económicas, la agenda de la sustentabilidad no solo no se detuvo, sino que, además, en algunos casos, se vio fortalecida. De este modo, D'angelo (2019) rastrea cinco tendencias centrales que priman en las estrategias actuales de responsabilidad social y sustentabilidad en las firmas argentinas. Ellas son para D’angelo (2009):

1. Igualdad de género: 2018 fue un gran año para la instalación de la agenda de género, con todo Argentina retrocedió al puesto 36 en el mundo - y séptimo en América Latina- en el Índice Global de la Brecha de Género elaborado por el Foro Económico Mundial.

2. Compliance y anticorrupción: Argentina en la actualidad necesita de una verdadera revolución ética en la forma de hacer negocios.

\section{Economía Circular.}

4. Fortalecimiento de la Agenda 2030 de ODS: las empresas asumieron que la incorporación de la Agenda 2030 de Objetivos de Desarrollo Sostenible debe ser una consecuencia de la sincera asunción de la responsabilidad de la compañía ante la sociedad, y no simplemente un objetivo de la estrategia empresarial. Por eso, de ahora en más el desafío más importante en este tema es la medición de impacto.

\section{Cadenas de Valor.}

De modo semejante Ulla (2018) plantea seis aspectos críticos de la RSE en el presente. Primero, el cumplimiento de los derechos humanos. Segundo, la equidad de género. Tercero, el cuidado del medio ambiente. Cuarto, el desarrollo sostenible. Quinto, La cadena de valor. Finalmente, la dimensión comunitaria.

En definitiva, Argentina no ha conseguido poca cosa, ha logrado diseñar una agenda actualmente. Es en estos temas que las empresas argentinas se encuentran estancadas en ciclos sucesivos de stop and go, con las dificultades propias de un país en constante cambio y sujeto a ciclos económicos muy disímiles los unos de los otros.

En resumen. Colombia dispone de muchas estadísticas producto de encuestas y serios trabajos de campo. México, por su parte, pone énfasis en premiar o distinguir a aquellas empresas destacadas mientras que Argentina si bien tiene interesantes organizaciones de seguimiento para las empresas, enfatiza en la construcción de una agenda de temas como marco común en que las empresas deben trabajar.

\section{DISCUSIÓN Y LIMITACIONES DEL ESTUDIO}

A pesar de los avances expuestos y del vertiginoso desarrollo de la disciplina, el informe identifica algunos clarososcuros en la actualidad. Existen a juicio de este trabajo determinadas áreas grises o lagunas donde es posible plantearse 
interrogantes o dudas sobre el funcionamiento del presente y del horizonte de la RSE en el mundo y fundamentalmente en América Latina.

En primer lugar, como se ha descrito en apartados anteriores, se detectan problemas en la medición de la RSE. Es verdad que las mediciones se han incrementado sustancialmente, aunque sigue habiendo empresas que siguen sin medir. El problema 0 conflicto radica en la falta de unificación de criterios para medir. Las mediciones se basan en diferentes metodologías como las de Gestión y resultados, la metodología GRI, y otras. A su vez, tanto en la OCDE, pero fundamentalmente en América Latina, lo que se contabiliza son datos de reportes financieros, siendo escasos los informes que contabilizan los no financieros. Es, sin lugar a dudas, una cuenta pendiente. Sin embargo, más allá de las diferencias, existe un consenso de que se ha achicado la brecha entre las distintas mediciones y existen expectativas de que se continuará por este camino.

En segundo plano, existe una marcada dificultad para conseguir información veraz y confiable sobre las mediciones. Son pocas las instituciones, organizaciones u asociaciones de empresas que levantan información y realizan investigaciones al respecto. Es quizás por eso que desde este trabajo se destacan enormemente el Informe Forética 2018 y el informe elaborado por KPMG, siendo de la información a la que se puede acceder, los más interesantes, completos y fidedignos informes disponibles. En general, lo que se encuentra son reportes particulares de empresas que disponen de un marcado interés propio y por ende dudoso, donde se pretende difundir más la reputación de la compañía que sobre su práctica actual en responsabilidad corporativa.

El tercer punto a señalar se propone debatir entre la dicotomía RSE-Publicidad. Este trabajo se pregunta hasta qué punto se utilizan los informes de RSE como una dimensión propia del negocio y hasta qué punto tienen una finalidad publicitaria para dar a conocer la empresa. El punto que nos proponemos analizar mediante esta investigación es el énfasis que las grandes empresas realizan en sus propios informes, y que sirven más para promover el buen nombre de la empresa de un modo ético o de prestigio, más que para cumplir con otro objetivo. De modo contrario, la RSE no sería vista como un deber inherente al negocio sino como una suerte de poder blando, atrayente frente a gobiernos y la sociedad. Un ejemplo claro de ello acontece en México donde se difunden por demás las acciones realizadas por las grandes empresas como Coca Cola, Grupo Bimbo, Syngenta, América Móvil, Bio-Pappel, Banamex, Cemex, HSBC, y Pemex ${ }_{10}$. Particularmente llamativos es el énfasis puesto en Cemex $_{11}$ y Pemex (Bosch Hernández, 2015). Vinculamos estos hechos a lo que el Informe Forética mencionaba que las firmas percibían a los ODS como una oportunidad para el sector privado.

10 Ver: https://www.gob.mx/salud/prensa/la-responsabilidad-social-empresarial-una-realidad-enmexico

11 Ver: https://www.expoknews.com/cemex-primer-lugar-del-ranking-de-responsabilidad-socialempresarial-2013/y

https://www.responsabilidadsocial.net/cemex-mexico-lider-en-rse-por-segundo-ano/ 
Del mismo modo, ha resultado difícil trascender del ámbito de las grandes empresas en América Latina. Son ellas y las asociaciones empresarias quienes miden y publican sus datos siendo extraño el cómputo de datos y acciones de pequeñas y medianas empresas en materia de RSE. Lo paradójico de la situación es que las PYMES en América Latina son el motor del empleo y movilizan el mercado de trabajo. Por lo tanto, desde este trabajo se considera que en esta región sería por demás importante realizar un esfuerzo y dedicación extra para contabilizar y medir las acciones de RSE en este vasto y heterogéneo universo de firmas.

En cuarto lugar, resulta particularmente llamativa la enumeración de acciones y porcentajes invertidos en el cuidado del medio ambiente. Los ODS y todos los informes ponen mucha relevancia en esta cuestión. Mitigación del impacto ambiental, reciclaje, reutilización del material, y previsión son lenguaje común dentro del mundo empresarial. En cierta forma es un gran progreso tener en cuenta el medio ambiente y tomar medidas en pos de un desarrollo sostenible. Sin embargo, cabe preguntarse ante el incremento de los problemas medioambientales si hay un cuidado o protección real del medio ambiente por parte de las empresas, 0 si se trata tan solo de slogans publicitarios para favorecer la imagen de las mismas. Desde este trabajo se sostiene que hay un reconocimiento de la problemática ambiental y que las empresas deben colaborar para ayudar en su solución, pero a la vez es necesario dar un paso más y crear un compromiso concreto de carácter cualitativo con objeto de alcanzar el desarrollo sostenible. Coincidimos con Alea García (2007) que "a pesar de todos los esfuerzos, programas, estrategias, iniciativas y experiencias concretas que se han implementado de responsabilidad social empresarial; estas no resultan aún suficientes para lograr la solución de la actual crisis socio-ambiental que enfrenta el planeta".

Quinto, es difícil valorar en muchos casos el papel de las empresas en el objetivo de combatir la pobreza y la desigualdad. Como se lo mencionó con anterioridad, la dimensión social es un aspecto específicamente relevante para las empresas. No obstante, se percibe que es insuficiente. ¿Por qué? 0 ¿En qué sentido es insuficiente? El futuro del trabajo es sumamente incierto, pero todos los pronósticos son pesimistas. Nadie sabe bien en qué medida, existe y existirá una tendencia a la mecanización, robotización del trabajo por lo que las empresas reemplazarán al hombre por la máquina. En la actualidad ya se vislumbra un creciente precarización y tercerización de cada vez más actividades laborales. Ante ese panorama cabe preguntarse si las empresas expulsan trabajadores o colaboran a disminuir y erradicar la pobreza y la inequidad. Por eso, se observa una actitud ambivalente al desarrollar capital y recursos humanos, capacitar trabajadores, beneficiar y amparar a sus familias, vincularse con la sociedad civil, promover la cultura y el deporte, realizar programas de inclusión para jóvenes y mujeres, pero por el otro lado no puede responder o prever el impacto de la incorporación de tecnología en el mercado de trabajo. 
Por último, y quizás el punto de discusión que este artículo pretende instalar, es si en verdad existe el concepto de RSE como un componente inherente a la empresa con el fin de ayudar al desarrollo sostenible, o simplemente es utilizado como una herramienta de crecimiento empresarial con la finalidad de incrementar los negocios. Desde esta investigación se pretende reflexionar hasta donde hay convergencia entre el crecimiento empresarial y la RSE, o si por el contrario hay una colisión entre estas categorías. Una respuesta simple a estos interrogantes es que la literatura al respecto está dividida: una parte considera a la RSE como una categoría ineludible dentro del crecimiento empresarial, mientras que la otra parte percibe que la RSE poco realiza por el desarrollo sostenible y funciona más como una estrategia de dar a conocer una empresa para vender más. 0 bien, desde el punto de vista medio ambiental, las acciones que se realizan para su protección poco impacto o resultado tienen en la realidad y son más funcionales como una pantalla para poder desarrollar sus negocios sin impedimentos por parte de sectores ecologistas.

No obstante, este trabajo propone otro enfoque. Se considera que la RSE como concepto $\mathrm{y} / 0$ categoría teórica es real y válida. Tiene un surgimiento, una consolidación, un desarrollo, una maduración, y un progreso por realizar. Surge para dar respuestas a problemas concretos del ámbito empresarial. Al respecto, desde el establecimiento de los ODS en 2015 es una realidad insoslayable y casi el único camino a seguir. Ir contra la corriente sería nocivo y perjudicial para cualquier empresa. Por eso no es posible perseguir crecimiento empresarial sin RSE, en otras palabras, son dos caras de una misma moneda. La RSE es como señala Jaillier Catrillón (2012) un componente de la ética empresarial.

Ahora bien, en muchos casos se percibe que este concepto teórico real, tangible no se aplica claramente 0 de manera pura el accionar de las empresas. De esta manera, se vislumbra una brecha entre la teoría y los hechos. La misma tiene a juicio de este trabajo dos motivaciones. La primera, es una inmadurez propia de la disciplina de la RSE. Como quedó expuesto en un apartado anterior, actualmente hay más planificación (pese a ser por períodos cortos de tiempo), más acciones, existe una profesionalización del área, pero el impacto de todo ese proceso no ha dado todos los resultados positivos que se esperaban en el ámbito social, económico y medioambiental. De ahí, que parte de la crítica sea válida. Como segunda motivación, y realmente preocupante son los "desvíos" que la disciplina sufre los cuales son propios de empresas con objetivos exclusivamente mercantilistas. En este caso suele afirmarse que las empresas se valen de la falta de regulación por algún organismo nacional e internacional además de no constituirse ninguna responsabilidad jurídica sino solo permanecer en el ámbito de la moral (una decisión de la empresa), y siendo utilizada como una cuestión de marketing para beneficiar sus productos y servicios (Sánchez Legrán, 2017).

Estos dos problemas deben ser solucionados de cara al futuro. El primero demandará más tiempo, mayor profesionalización y transparencia. El segundo tiene y puede ser corregido en el corto plazo con más compromiso, control, y un entorno 
más exigente. Precisamente, como se expresará en los primeros apartados en esta etapa se espera que las normas y regulaciones se volverán más rígidas y exigentes.

Como cierre se observa, tal como señala el Informe KPMG, un vertiginoso y hasta espectacular progreso en América Latina. Sin embargo, esto no ha estado exento de desprolijidades. Primero, Latinoamérica es una región muy vasta y heterogénea donde no todos los países tienen el mismo compromiso y miden del mismo modo su responsabilidad corporativa. Es más, no todos los países y firmas entienden lo mismo por RSE, sino que algunos aún lo asocian a "balance social" 0 a "ética social". Segundo, las mediciones suelen concentrarse en empresas multinacionales, grandes empresas nacionales y compañías de propiedad estatal o mayoría accionaria estatal, descuidando o debiendo incluir el ámbito de las PYMES. Finalmente, resulta llamativo que en una región donde ha predominado en el siglo XXI el modelo extractivista basado en la explotación de recursos naturales y la intensificación de problemas y hasta algunos desastres ambientales, hayan aumentado correlativamente las acciones RSE ligadas al desarrollo sostenible y se hayan presentado como un gran logro sin haber considerado el impacto de dichas medidas (el cual dudosamente sea beneficioso). Justamente, el informe KPMG indica como sectores de mayor crecimiento (ya no rezagados) al petróleo y gas, y al sector forestal y papel (no así a la minería y megaminería).

En consecuencia, en su acelerado progreso en materia de RSE, América Latina y sus compañías deberán decidir si practican la RSE como una dimensión ética del negocio 0 si bien es un elemento para obtener el máximo de rentabilidad posible. En ese sentido, no queda claro, sino que se vislumbra una zona gris en la que cabe preguntarse ¿Quo Vadis América Latina?

Por otro lado, al mismo tiempo, se deja constancia que una de las limitaciones 0 de las problemáticas para estudiar esta actividad o disciplina han resultado las escasas estadísticas a las que se puede acceder, y por, sobre todo, la veracidad de las mismas. A juicio de este trabajo son pocos los informes fiables puesto que gran parte de los mismos han sido elaborados por las propias empresas bajo sus intereses careciendo de objetividad o con metodologías no recomendadas. Esta situación limita cualquier análisis al disponer de un débil insumo principal como son los datos estadísticos. Esta situación se acrecienta en el caso de América Latina ya que este tipo de información es todavía más escasa y minúscula.

\section{CONCLUSIONES}

A lo largo de este trabajo se afirma que la Responsabilidad Social Empresarial es una disciplina que llegó para quedarse. Se ha consolidado, ha madurado, progresado y continuará haciéndolo en el futuro inmediato. Tiene actualmente alcance universal, aunque no se dispone de una definición unívoca de la misma ni existe una organización nacional o internacional que la regule y controle. 
El elemento disparador del nuevo impulso es la toma de conciencia de la comunidad internacional plasmada en los 17 Objetivos de Desarrollo Sostenible de la Agenda 2030 de la ONU, en la cual para su cumplimiento se requiere de la coordinación entre sector público (gobiernos), sector privado (empresas) y la sociedad (ciudadanos y consumidores). Desde la responsabilidad empresarial lo que hasta ese momento revestía carácter voluntario, se convirtió a su vez tanto en un poderoso compromiso como al mismo tiempo en una presión del entorno.

Si bien la agenda de la RSE es muy amplia, se centra básicamente en tres grandes áreas: lo social, el respeto y fomento de los derechos humanos, y el cuidado y la preservación del medio ambiente. En estos temas, las empresas de todos los sectores han realizado progresos incluso, aquellos sectores que se encontraban algo rezagados algunos años atrás como sanidad, industria manufacturera, transporte \& ocio, y metales.

Como se mencionó anteriormente, el avance en la RSE es una tendencia mundial, aunque se manifiesta con distintas intensidades en cada región. Primero los países miembros en la OCDE son quienes se encuentran más proclives a cumplir y aplicar Ios ODS. El resto viene más retrasado en ese sentido. Lo mismo acontece en cuanto a la RSE solo que al contabilizarla Europa computa como una unidad en algunos informes y la relegada Europa Oriental fracciona sobre la Occidental. Estados Unidos y Canadá están mejor posicionados. Lo novedoso en los informes de 2017 y 2018 es el crecimiento en la medición de América Latina.

A pesar de este progreso, la región manifiesta una gran heterogeneidad. De la información a la que se ha podido acceder se destacan la enorme sistematicidad de datos que Colombia recuenta de sus empresas a través de la ANDI destacando como positivos aspectos cuantitativos de la medición y la profesionalización del área, y como déficit, aspectos cualitativos como la metodología, la escasa planeación y la falta de financiamiento. Por su parte, México mantiene un pujante sistema de reconocimiento y premiación de las empresas responsables lo que ha ayudado a difundir prácticas y conocimientos en la materia. Aun así, mantiene llamativamente como pilares de estas prácticas a las grandes empresas nacionales y multinacionales, incluidas las grandes empresas estatales 0 con participación estatal en desmedro de las pequeñas y medianas. Por último, el caso de Argentina que, si bien es difícil conseguir información cuantificable, este país ha focalizado en diseñar una agenda tratando de unificar los temas sobre los que las empresas deben trabajar.

Sin embargo, una de las conclusiones más relevantes es la existencia de zonas grises o lagunas en la RSE. Primero, no hay una definición del concepto, por ende, muchas empresas lo definen de diferente manera. Por ejemplo, se confunden de este modo lo conceptos de RSE, Balance Social y Ética Empresarial. Segundo, ante la pregunta i¿cómo se mide?, hay diferentes respuestas. Si bien en este punto cada vez hay más estandarización de la metodología con una preponderancia del método GRI, coexisten múltiples formas siendo algunas de ellas reportes de gestión de las 
propias empresas. 0 sea, ¿quién mide?, ¿bajo qué criterios? y, ¿con qué intención adquiere gran relevancia? Tercero, se computa información financiera, pero, resta reportar la información no financiera de las empresas. Muy pocas y un número selecto de países lo hacen. Cuarto, se tiene en cuenta información de las grandes empresas, pero todavía hay que avanzar en materia de PYMES. Finalmente, no hay estimaciones de impacto sobre las acciones de RSE. Es actualmente el punto más endeble de las empresas en la materia, siendo que la esencia debería ser mostrar los resultados de dichas acciones.

Por último, los informes indican el nacimiento de una nueva etapa en donde se abren perspectivas para dar principio de solución a algunos de estos vacíos e interrogantes. Se estima que las regulaciones serán más exigentes, mayores las precisiones metodológicas, y se pondrá mayor énfasis en el impacto de las acciones de RSE que en la mera definición. En definitiva, se transita hacia una profesionalización de la actividad. De este modo, se podría erradicar la utilización de la RSE como un medio que beneficie en enfoque mercantilista que tiene como fin la ganancia y el crecimiento empresarial, para dar lugar a la RSE como un elemento ineludible y central de la práctica empresarial.

\section{BIBLIOGRAFÍA}

ALEA García, A. (2007). Responsabilidad Social Empresarial. Su contribución al desarrollo sostenible. Publicado en Revista Futuros No. 17, 2007 Vol. V.

ANDI. (2017). Panorama de la gestión social de 500 empresas en Colombia. Informe de la Asociación Nacional de Empresarios de Colombia.

AGUILERA Castro, A. Puerto Becerra, D. (S/F). Crecimiento empresarial basado en la Responsabilidad Social. Pensamiento y gestión. №32.ISSN 1657-6276. Colombia.

BARROSO Tanoira, F. (2008). La responsabilidad social empresarial. Un estudio en cuarenta empresas de la ciudad de Mérida, Yucatán. Contaduría y Administración. No. 226. Pp.73-91.

BOSCH Hernández, B. (2015). "PEMEX está pasando al proceso de compartir su RSE". Corresponsables. Consultado el 14 de noviembre de 2019. Recuperado de: https://mexico.corresponsables.com/actualidad/pemexesta-pasando-al-proceso-de-compartir-su-rse

CARDONA Acevedo, M. Duque Orozco, Y. (2013). Responsabilidad Social Empresarial: Teorías, índices, estándares y certificaciones. Cuadernos de Administración. Universidad del Valle. Vol. 29 № 5. 
CARROLL, A. (1991). The pyramid of corporate social responsibility: toward the moral management of organizational stakeholders. Business Horizons, 34(4), 39-48.

CEMEFI. (2018). Informe Anual. Centro Mexicano para la Filantropía. 30 años. Consultado el 8 de noviembre de 2019.Recuperado de: https://www. cemefi.org/informes/informe2018/Informe18ESP.pdf

CORREA Jaramillo J. (2007). Evolución Histórica de los conceptos de Responsabilidad Social Empresarial y Balance Social. Semestre Económico, volumen 10, №. 20, pp. 87-102 - ISSN 0120-6346. Medellín-Colombia.

D'ANGELO, J. (2019). Logros y Agenda pendiente de la responsabilidad social en Argentina. Télam. Buenos Aires.

DUQUE Orozco, Y. Cardona Acevedo, M. y Rendón Acevedo J. (2013). Responsabilidad Social Empresarial: Teorías, índices, estándares y certificaciones. Cuadernos de Administración. Universidad del Valle, Colombia. Vol. 29, №50.

FRIEDMAN, M. (13/09/1970). The social responsibility of business is to increase its profits. The New York Times. Magazine, pp. 1-6.

JAILLIER Catrillón, C. (2012). La Ética y la Responsabilidad Social en los negocios. Revista Latinoamericana de Publicidad. Vol.1, Núm.1. Unidad Pontificia Bolivariana. ISSN: 2422-1619.

KPMG. (2018). El camino por recorrer. Estudio KPMG sobre reporting de responsabilidad corporativa 2017. España. Recuperado de: Kpmg.com

MCWILLIAMS, A., Siegel, D. y Wright, D. (2006). "Introduction by Guest Editors Corporate Social Responsibility: International”, Journal of Business Strategies; Spring 2006; 23, 1.

PORTO, N. Castromán, J. (2006). Responsabilidad social: un análisis de la situación actual en México y España, Contaduría y Administración, Núm. 220, pp. 67-87.

PÉREZ Espinoza, M. J., Espinoza Carrión, C., \& Peralta Mocha, B. (2016). La responsabilidad social empresarial y su enfoque ambiental: una visión sostenible a futuro. Revista Universidad y Sociedad, 8(3), 169-178.

RAMíREZ Alcántara, H. y Morales Espinoza M. (2008). La Responsabilidad Social Empresarial en México. Congreso Aderse 2008. 
REMACHE, R. Villacis, S. y Guayta, N. (2017). La Responsabilidad Social vista desde un enfoque teórico. Revista Científica Dominio de las Ciencias. Vol. 4, núm 1. ISSN: 2477-88181, pp. 550-568.

RUBIO, M. M. R., Torres, S. V., \& Toapanta, N. A. G. (2018). La responsabilidad social empresarial vista desde un enfoque teórico. Dominio de las Ciencias, 4(1), 550-568.

SÁNCHEZ Legrán, P. (2017). ¿Existe la Responsabilidad Social de las empresas 0 es solo marketing? Blog Consumerismo. Consultado el 1 a de noviembre de 2019. Recuperado de: https://www.facua.org/es/ noticia.php?ld=11536

SILOS, Jaime, et al. "Informe FORÉTICA 2018: sobre la evolución de la RSE y Sostenibilidad-La recompensa del optimista." (2018).

ULLA, L. (2018). Con más de 20 años en el país, la Responsabilidad Social Empresaria, ¿pasó de moda? Infonegocios. Consultado el 15 de noviembre de 2019. Recuperado de: https://infonegocios.info/enfoque/ con-mas-de-20-anos-en-el-pais-la-responsabilidad-social-empresariapaso-de-moda 